\title{
Effect of days to conception in the previous lactation on the risk of death and live culling around calving
}

\author{
P. J. Pinedo and A. De Vries ${ }^{1}$ \\ Department of Animal Sciences, University of Florida, Gainesville 32611
}

\begin{abstract}
The objective was to quantify the effect of days to conception (days open) in the previous parity on the risk of death and live culling (excluding the disposal reasons "dairy purposes" and "death") in the proximity of a subsequent calving in Holstein cows enrolled in the Dairy Herd Improvement program. After edits, 2,075,834 observations of cows calving between 2001 and 2007 in herds located in 36 US states primarily east of the Mississippi river were available. The period at risk included the time between $14 \mathrm{~d}$ before expected calving to $60 \mathrm{~d}$ after calving. Days open were categorized in 6 periods: 0 to $45 \mathrm{~d}, 46$ to $90 \mathrm{~d}, 91$ to $150 \mathrm{~d}, 151$ to $210 \mathrm{~d}, 211$ to $300 \mathrm{~d}$, and 301 to $600 \mathrm{~d}$ after calving in the previous parity. Other variables of interest included parity, length of the dry period before calving, relative last test-day milk yield before dry off before calving, season of calving, and the cow's relative 305-d mature equivalent (305ME) milk yield before calving. Control variables were calving year, herd size, and relative herd $305 \mathrm{ME}$ milk yield. All variables were categorized. Generalized mixed models were used and included herd as random effect. Interactions between days open and the variables of interest were included in the models. Least squares means for the risk of death between -14 and $60 \mathrm{~d}$ after calving were $2.5,2.5,2.9,3.6,4.4$, and $5.8 \%$ for increasing categories of days open. Similarly, for the same categories, least squares means for the risk of live culling were $4.5,5.0,5.4,6.1,6.9$, and $8.1 \%$. The effect of days open on the risk of death was slightly greater for third-parity cows, for long dry periods, for cows with low test-day milk yield before dry off before calving, for spring calvings, and for intermediate relative $305 \mathrm{ME}$ milk yield before calving. Similar trends for these interactions were found for the risk of live culling, except for relative $305 \mathrm{ME}$ milk yield before calving, where the effect of days open was more pronounced for highproducing cows. In conclusion, increased days open in
\end{abstract}

Received May 21, 2009.

Accepted November 6, 2009.

${ }^{1}$ Corresponding author: devries@ufl.edu the previous parity were associated with a greater risk of death and live culling around calving.

Key words: death, live culling, risk, days open

\section{INTRODUCTION}

Days to conception (days open) after calving depends on multiple factors such as voluntary waiting period, AI techniques, season of calving, management policies, herd size, production level, and parity (Oseni et al., 2003). Although days open has been extensively used as a measure of the success of reproductive programs, a paucity of information exists on its effect on survival in a subsequent parity. Such an association needs to be considered when the economic value of decreased days open is calculated, but this is not typically done. Dairy producers are aware that cows with extended days open have more health problems, including potentially an increased risk of culling.

Extended days open may increase the risk of overconditioning of cows toward the end of their lactation because milk yield is then typically lower, and feed intake is less reduced. These cows may have an increased risk of death or live culling around the subsequent calving because of related metabolic problems (Fronk et al., 1980; Chassagne et al., 1999; Heuer et al., 1999). This combination of disease conditions in the obese cow has been termed the "fat cow syndrome" (Morrow, 1976). During early lactation, body fat is utilized as a source of energy, increasing the availability of fatty acids. However, the liver of an overconditioned cow is more limited in its ability to oxidize fatty acids than that of a thinner cow (Goff and Horst, 2007), favoring ketosis and other health disorders. Cows with a BCS $\geq 4$ at dry off were more likely to develop cystic ovarian, foot problems after calving, and reproductive problems including metritis (Gearhart et al., 1990), and were also more affected by milk fever (Heuer et al., 1999). Moreover, longer days open in Jersey cows resulted in longer dry periods (Kuhn et al., 2007), contributing to the risk of overconditioning.

Increased body condition is not the only explanation for a possible positive association between days open and increased risk of culling. It is possible that health 
problems before conception resulted in longer days open but also directly contributed to a greater risk of death and live culling around the next calving. Genetics could play a role in the association between days open and the risk of death and live culling around calving.

Lower survival rates are a concern on dairy farms from both a well-being and an economic point of view, and the issue could be particularly relevant for expanding dairy herds (Weigel et al., 2003). A trend for lower survival from 1980 to 2000 was documented for Holstein cows, with a reduction of 4.0 and 6.3 percentage points in annual survival rate to parity 2 and 3, respectively (Hare et al., 2006). Similarly, Miller et al. (2008) reported an increase of 1.6 percentage points in the frequency of deaths per lactation from 1995 to 2005 across the United States. In addition, the greatest risk of live culling was in early lactation and after 420 d post-calving (Fetrow et al., 2006), with live culling risks close to $8 \%$ by $60 \mathrm{~d}$ after calving (Dechow and Goodling, 2008). From an economic perspective, live culling and death early in lactation are costly. Opportunity losses of a live culled average second-parity cow shortly after calving may be $\$ 1,500$; for death this may be $\$ 2,000$ (De Vries, 2006).

The central hypothesis was that increased days open in the prior parity increased the risk of live culling and death in the period around the subsequent calving. Moreover, the interaction of days open with other factors such as milk yield before dry off and length of the dry period may influence this association. Therefore, the objective was to quantify the effect of days open in the previous parity on the risk of death and live culling in the proximity of a subsequent calving in Holstein cows enrolled in the DHI program.

\section{MATERIALS AND METHODS}

\section{Study Population}

The initial data set consisted of 15,766,579 lactation records of cows calving between 2001 and 2007 that were provided by Dairy Records Management Systems (Raleigh, NC) from all DHI herds located in 36 US states east of the Mississippi river. Briefly, relevant data per record consisted of calving date, parity, date of dry off, test-day dates, test-day milk yields, test-day fat and protein percentages, herd code, reproductive status, and disposal code and date. Disposal codes included the following 10 reasons: "feet and legs," "dairy purposes," "low production," "reproduction," "injury or other," "mastitis," "disease," "udder problems," "died," and "reason-not-reported." Live culling was considered removal from the herd with any disposal code other than "died" or "dairy purposes." Insemination dates were only available for the last known lactation of the cow. Date of conception was available for completed lactations. No information about health disorders was available in the data set. Very limited body condition score data was available and therefore was not included in the analyses.

\section{Data Edits}

The analyses were restricted to Holstein cows that survived the first parity or were live culled or died within $14 \mathrm{~d}$ before the expected calving date. Records with missing parity number, calving date, or from herds with fewer than 100 milking cows in each year were removed from the data set. Records were also excluded if the last reported date was an event other than live culling or death and occurred between -14 to $60 \mathrm{~d}$ around the calving of interest, with no evidence of survival after 60 $\mathrm{d}$ after calving. Records with days to conception $>600$ were also excluded.

\section{Variables of Interest}

Outcome variables were the risk of live culling and the risk of death between $14 \mathrm{~d}$ before the expected calving date to $60 \mathrm{~d}$ after calving. Both risks were analyzed separately. Cows without a calving event were considered at risk between $14 \mathrm{~d}$ before and $14 \mathrm{~d}$ after the expected calving date. The justification was that the expected calving date is an estimate based on the last recorded insemination date but the actual calving date is unknown. When the cow is live culled or dies around calving, the calving event may not be reported (Dechow and Goodling, 2008). Extending the risk period to $\pm 14 \mathrm{~d}$ around the expected calving date includes such events.

The main variable of interest was days open in the previous parity, defined as the number of days between calving and the reported insemination that resulted in pregnancy. The gestation length was estimated to test the accuracy of the last reported insemination date. Consequently, if the resulting gestation length was $<220 \mathrm{~d}$ or $>300 \mathrm{~d}$, the conception date was calculated as the subsequent calving date $-280 \mathrm{~d}(0.14 \%$ of all final records). When the subsequent calving date was missing but a due date was reported, the conception date was calculated as $280 \mathrm{~d}$ before the provided due date. If a cow did not have a reported due date, but was reported pregnant, then her last insemination date was used as the conception date. The due date was then estimated as conception date $+280 \mathrm{~d}$.

Other variables of interest included parity at the subsequent calving, length of the dry period before calving, relative last test-day milk yield before dry off before 
calving, season of subsequent calving, and the cow's relative 305-d mature equivalent (305ME) milk yield before calving. Relative last test-day milk yield before dry off was estimated as the deviation of the cow's milk yield from the average of her herdmates calving in the same year and season. Similarly, relative 305ME milk yield was estimated as the deviation from the DHIprovided herdmates' 305ME milk yield average.

Control variables included calving year, herd size, and relative herd 305ME milk yield, estimated as the deviation of the herd 305ME milk yield from the population average in the same year and season. Risks of herd live culling and death for the period of interest by year and season of (expected) calving date were also estimated and included in the models when the alternate outcome was analyzed (e.g., herd death risk was included when live culling was the outcome variable of interest). Given that an inverse association between live culling in early lactation and level of mortality had been reported (McConnel et al., 2008), it was expected that low mortality rates in some herds may not be the result of greater survivability but the effect of premature live culling. Therefore, the inclusion of these variables in the models was intended to adjust for the possibility of lower death risk in herds when the risk of early live culling was great and vice versa.

The distribution of the continuous variables was examined through the use of histograms and descriptive statistics (e.g., means, medians, and standard deviations) to assist in the subsequent categorization of the variables of interest and control variables. The variables last test-day milk yield before dry off, cow's 305ME milk yield, and herd 305ME milk yield were expressed as relative values deviated from the mean and were categorized as $<$ mean $-\mathrm{SD}$, mean $-\mathrm{SD}$ to mean $+\mathrm{SD}$, and $>$ mean + SD.

Continuous variables of interest were categorized as follows. Days open in the previous parity: 1 to $45 \mathrm{~d}$, 46 to 90 d, 91 to 150 d, 151 to 210 d, 211 to $300 \mathrm{~d}$, and 301 to $600 \mathrm{~d}$; parity: 2,3 , and $\geq 4$; length of the previous dry period: $<41 \mathrm{~d}$ (short), 41 to $70 \mathrm{~d}$ (intermediate), and $>70 \mathrm{~d}$ (long); relative last test-day milk yield before dry off calculated as the difference from the herd mates' average: $<-8.25 \mathrm{~kg} / \mathrm{d}$ (low), -8.25 to $8.25 \mathrm{~kg} / \mathrm{d}$ (intermediate), and $>8.25 \mathrm{~kg} / \mathrm{d}$ (high); and season of calving: winter (January to March), spring (April to June), summer (July to September), and fall (October to December). Relative 305ME milk yield was calculated as the difference from the DHI-reported herd mates' average milk yield: $<-1,549 \mathrm{~kg}$ (low), $-1,549$ to $1,938 \mathrm{~kg}$ (intermediate), and $>1,938 \mathrm{~kg}$ (high).

Continuous control variables were categorized as follows. Herd size: 100 to 150,151 to 300,301 to 450, 451 to 900,900 to 1,800 , and $>1,800$ cows; relative herd
305ME milk yield was calculated as the difference from the herd-year-season average: $<-384 \mathrm{~kg}$ (low), -384 to $384 \mathrm{~kg}$ (intermediate), >384 kg (high); herd live culling risk for the period of interest by year and season: $<2.0 \%$ (low), 2.0 to $9.8 \%$ (intermediate), and $>9.8 \%$ (high); and herd death risk for the period of interest by year and season: $<0.7 \%$ (low), 0.7 to $6.6 \%$ (intermediate), and $>6.6 \%$ (high).

\section{Statistical Analysis}

Considering the delimited period at risk and the binary nature of the outcome variables, logistic regression was used for the analysis, and generalized linear models were fitted to the data. The effect of the variables of interest on the odds and risks of live culling and death were estimated by using the logit link in the GLIMMIX procedure in SAS (release 9.2, SAS Institute Inc., Cary, NC). The models included herd as random effect with the categorized variables of interest and control variables considered as fixed effects. Cows might have multiple observations. The inclusion of the variable cow as a random effect to account for the effect of repeated measures was not possible because the GLIMMIX procedure failed to converge. A general effect of ignoring to account for repeated measures is that the standard errors of the parameter estimates will often be too small (Dohoo et al., 2003).

Interactions between the effect of days open and parity at calving, length of the dry period before calving, relative last test-day milk yield before dry off before calving, season of calving, and the cow's relative 305ME milk yield before calving were included in the models. Effects were considered significant when $P \leq 0.05$. Only the control variables, the variables of interest, and the significant interactions between days open in the previous parity and variables of interest were included in the final models.

The estimates from the final models were expressed directly as least squares means (LSM) of the probabilities of occurrence of each outcome (Bar et al., 2008). Estimated probabilities were presented as the risk (\%) of live culling or death during the period at risk $(-14$ to $60 \mathrm{~d}$ after calving). Odds ratios (OR) were also estimated to facilitate comparison with results reported in the literature. Differences in the average risks of death and live culling between 46 to $90 \mathrm{~d}$ and 210 to $300 \mathrm{~d}$ open were estimated by herd to describe the distributions of these effects between herds.

\section{RESULTS AND DISCUSSION}

After edits, 2,075,834 observations in 1,626 herds were available for the analysis. Means and percentiles 
Table 1. Means and percentiles of descriptive statistics of data used in this study

\begin{tabular}{|c|c|c|c|c|c|c|}
\hline Variable & Mean & \multicolumn{5}{|c|}{ Percentile } \\
\hline Days open in the previous parity & 146.5 & 61 & 79 & 119 & 188 & 276 \\
\hline Last test-day milk yield (kg) & 21.0 & 8.6 & 14.1 & 20.9 & 27.2 & 33.0 \\
\hline Relative last test-day milk yield $(\mathrm{kg})$ & 0 & -10.6 & -5.6 & 0.0 & 5.5 & 10.4 \\
\hline Cow $305 \mathrm{ME}^{2}$ milk yield $(\mathrm{kg})$ & 11,353 & 8,283 & 9,783 & 11,374 & 12,959 & 14,417 \\
\hline Relative herd 305ME milk yield ${ }^{4}(\mathrm{~kg})$ & 0 & -420.9 & -190 & 9 & 203 & 409 \\
\hline Herd live culling risk ${ }^{5}(\%)$ & 5.9 & 2.0 & 3.4 & 5.4 & 7.6 & 10.0 \\
\hline Herd death risk $(\%)$ & 3.7 & 1.0 & 1.9 & 3.1 & 4.7 & 6.6 \\
\hline
\end{tabular}

of descriptive statistics are presented in Table 1. Overall, the crude (unadjusted) risks of death or live culling during the period at risk were 4.3 and $6.6 \%$, respectively. Of the live culled cows, $7 \%$ were culled before the expected calving date. Of the dead cows, $11 \%$ died before the expected calving date. All control variables were significant and were included in the final model.

Miller et al. (2008) reported a death frequency of $3.1 \%$ per lactation, and the NAHMS Dairy 2007 survey reported an annual death rate of 4.8 to $6.1 \%$, depending on herd size (USDA, 2007). Annual death rates ranging from 5.9 to $7.7 \%$ were reported for various regions in the United States during 1998 (Smith et al., 2000). In contrast to our results for the period around calving, which resulted in similar levels of risk, it appears that the greatest risk of death is in early lactation (Table 2).

Previous reports also indicated that a high proportion of death occurred during the transition period around calving. Forty-two percent of overall mortality took place during the first $60 \mathrm{~d}$ after calving, with $52 \%$ of deaths occurring between $21 \mathrm{~d}$ before the expected calving date and $60 \mathrm{~d}$ (Hadley et al., 2006; Dechow and Goodling, 2008). The risk of death in the present study is slightly greater than that reported earlier. The exclusion of first parity may explain these differences, considering that mortality in the first parity is lower, and some deaths around calving may not be reported to DHI (Dechow and Goodling, 2008). A greater risk of culling in early lactation was also reported by Fetrow et al. (2006).

An annual live culling rate of $28.2 \%$ was reported for DHI herds in 10 states during the period from 1993 to 1999 (Hadley et al., 2006), and an annual rate of
$23.1 \%$ was estimated for Pennsylvania herds (Dechow and Goodling, 2008). That study reported a risk of live culling of $5.6 \%$ during the first $60 \mathrm{~d}$ after calving, which represents about $21 \%$ of the live culling in the complete lactation. Therefore, the majority of live culling occurs after $60 \mathrm{~d}$.

The risk of death increased with herd size category from 3.2 to $3.7 \%$ for smallest to largest herds, respectively, which is consistent with the trend reported for this association (Smith et al., 2000; Hadley et al., 2006; Dechow and Goodling, 2008). Conversely, there was no clear association between herd size and risk of live culling in this study, which is in opposition to a positive association reported by Hadley et al. (2006). The risk of death was greatest for herds with intermediate herd 305ME milk yields (3.5\%). Similarly, herds with an intermediate level of milk yield showed the greatest risk for live culling (5.9\%). The correlation between the annual herd death risk around calving and herd live culling risk around calving was $0.18(P<0.001)$. Thus, herds that had a greater risk of live culling tended to have a greater risk of death around calving.

\section{Effect of Days Open}

The frequencies of observations per days open category from 1 to 45 through 301 to 600 d were 3,31 , $30,17,12$, and $8 \%$. Overall, LSM for the risk of a cow leaving the herd around calving through the combined risk of live culling or death were 7.0, 7.5, 8.3, 9.7, 11.3, and $13.9 \%$ for increasing categories of days open from 1 to $45 \mathrm{~d}$ through 301 to $600 \mathrm{~d}$ (Table 2). Least squares means for the risk of death were $2.5,2.5,2.9,3.6,4.4$, and $5.8 \%$ for increasing categories of days open in the 
Table 2. Risk (\%) of death or live culling (LSM \pm SE) between $14 \mathrm{~d}$ before expected calving and $60 \mathrm{~d}$ after calving by categories of days open in the previous parity, parity at calving, length of the dry period before calving, relative last test-day milk yield before dry off before calving, season of calving, and the cow's relative 305-d mature equivalent (305ME) milk yield before calving

\begin{tabular}{|c|c|c|}
\hline Variable & Death & Live culling \\
\hline \multicolumn{3}{|c|}{ Days open in the previous parity } \\
\hline 1 to 45 & $2.48 \pm 0.14$ & $4.51 \pm 0.21$ \\
\hline 46 to 90 & $2.52 \pm 0.07$ & $5.00 \pm 0.12$ \\
\hline 91 to 150 & $2.89 \pm 0.08$ & $5.41 \pm 0.13$ \\
\hline 151 to 210 & $3.60 \pm 0.11$ & $6.05 \pm 0.15$ \\
\hline 211 to 300 & $4.36 \pm 0.14$ & $6.87 \pm 0.19$ \\
\hline 301 to 600 & $5.79 \pm 0.22$ & $8.06 \pm 0.27$ \\
\hline \multicolumn{3}{|l|}{ Parity } \\
\hline 2 & $2.24 \pm 0.07$ & $3.92 \pm 0.10$ \\
\hline 3 & $3.55 \pm 0.10$ & $6.13 \pm 0.15$ \\
\hline$\geq 4$ & $5.09 \pm 0.14$ & $8.37 \pm 0.19$ \\
\hline \multicolumn{3}{|l|}{ Previous days dry } \\
\hline$<41 \mathrm{~d}$ & $2.90 \pm 0.09$ & $5.90 \pm 0.15$ \\
\hline 41 to $70 \mathrm{~d}$ & $3.28 \pm 0.09$ & $4.99 \pm 0.12$ \\
\hline$>70 \mathrm{~d}$ & $4.28 \pm 0.12$ & $6.89 \pm 0.17$ \\
\hline \multicolumn{3}{|c|}{ Relative last test-day milk yield ${ }^{1}$} \\
\hline$<-8.25 \mathrm{~kg} / \mathrm{d}$ & $4.43 \pm 0.14$ & $6.99 \pm 0.18$ \\
\hline-8.25 to $8.25 \mathrm{~kg} / \mathrm{d}$ & $3.27 \pm 0.09$ & $5.71 \pm 0.13$ \\
\hline$>8.25 \mathrm{~kg} / \mathrm{d}$ & $2.81 \pm 0.09$ & $5.07 \pm 0.14$ \\
\hline \multicolumn{3}{|l|}{ Calving season } \\
\hline Winter & $3.34 \pm 0.10$ & $5.63 \pm 0.14$ \\
\hline Spring & $3.72 \pm 0.11$ & $6.08 \pm 0.15$ \\
\hline Summer & $3.64 \pm 0.10$ & $6.30 \pm 0.15$ \\
\hline Fall & $3.10 \pm 0.09$ & $5.53 \pm 0.13$ \\
\hline \multicolumn{3}{|c|}{ Relative 305ME milk yield ${ }^{2}$} \\
\hline$<-1,549 \mathrm{~kg}$ & $3.43 \pm 0.10$ & $7.34 \pm 0.18$ \\
\hline$-1,549$ to $1,938 \mathrm{~kg}$ & $3.22 \pm 0.09$ & $5.51 \pm 0.13$ \\
\hline$>1,938 \mathrm{~kg}$ & $3.68 \pm 0.12$ & $5.00 \pm 0.15$ \\
\hline
\end{tabular}

${ }^{1}$ Deviated from herd-year-season average.

${ }^{2}$ Deviated from DHI provided herd mates' average.

previous parity. These results indicate a clear trend of greater risk of death for increasing number of days open (Table 2). It follows that the odds of death were reduced for cows with fewer days open in the previous parity when compared with cows with prolonged days open (Table 3 ). Cows in the category 300 to $600 \mathrm{~d}$ were 2.4 times more likely to die $(1 / 0.41)$ than were cows in the categories 1 to $45 \mathrm{~d}$ and 46 to $90 \mathrm{~d}$ open (Table $3)$.

Least squares means for the risk of live culling for the period at risk were $4.5,5.0,5.4,6.1,6.9$, and $8.1 \%$ for increasing categories of days open (Table 2). Similar to the risk of death, the results showed an association among increasing categories of days open and greater risk of live culling. Consequently, the odds of live culling increased when days open in the previous parity were extended; cows in the category 300 to $600 \mathrm{~d}$ were 1.85 and 1.66 times more likely to be culled than were cows in the categories 1 to $45 \mathrm{~d}$ and 46 to $90 \mathrm{~d}$ open (Table 3).

This association between death risk and days open is in agreement with the data presented by McConnel et al. (2008). They showed that herds with an average calving interval $>13.9$ mo were 1.78 times more likely to have a greater level of death than were herds with an average calving interval of $<13$ mo. Weigel et al. (2003) reported a greater risk of live culling for low-producing cows with a calving interval $>15$ mo.

The main change in the relative frequency of reasonspecific culling within categories of number of days open was for the reasons "low production" and "died." The relative frequency of culling for "low production" compared with the total number of cows culled decreased from 10.5 to $5.0 \%$ for the categories 1 to $45 \mathrm{~d}$ and 301 to $600 \mathrm{~d}$, respectively. Conversely, the relative frequency of culling with reason "died" ranged from 33.9 to $48.6 \%$ for the categories 1 to $45 \mathrm{~d}$ and 301 to $600 \mathrm{~d}$, respectively. The relative frequency of culling for "reproduction" was $6.5 \%$ for the category 1 to 45 $\mathrm{d}$ and ranged between 3.2 and $3.9 \%$ for the remaining categories.

The association between days open and the risk of death and live culling depended on the herd (Table 4). More than $10 \%$ of the herds showed a decrease in the risk of live culling and death when days open increased from the category 46 to $90 \mathrm{~d}$ to the category 210 to 
Table 3. Odds ratios for death or live culling between $14 \mathrm{~d}$ before expected calving and $60 \mathrm{~d}$ after calving by categories of days open in the previous parity, parity at calving, length of the dry period before calving, relative last test-day milk yield before dry off before calving, season of calving, and the cow's relative 305-d mature equivalent (305ME) milk yield before calving

\begin{tabular}{|c|c|c|c|c|}
\hline \multirow[b]{2}{*}{ Variable } & \multicolumn{2}{|c|}{ Death } & \multicolumn{2}{|c|}{ Live culling } \\
\hline & Odds ratio & $95 \% \mathrm{CI}^{1}$ & Odds ratio & $95 \% \mathrm{CI}$ \\
\hline \multicolumn{5}{|c|}{ Days open in the previous parity } \\
\hline 1 to 45 & 0.41 & $0.37-0.47$ & 0.54 & $0.49-0.60$ \\
\hline 46 to 90 & 0.42 & $0.39-0.45$ & 0.60 & $0.57-0.64$ \\
\hline 91 to 150 & 0.48 & $0.45-0.52$ & 0.65 & $0.62-0.69$ \\
\hline 151 to 210 & 0.61 & $0.57-0.65$ & 0.74 & $0.69-0.78$ \\
\hline 211 to 300 & 0.74 & $0.69-0.80$ & 0.84 & $0.79-0.90$ \\
\hline 301 to 600 & 1 & & 1 & \\
\hline \multicolumn{5}{|l|}{ Parity } \\
\hline 2 & 0.43 & $0.41-0.44$ & 0.45 & $0.44-0.46$ \\
\hline 3 & 0.69 & $0.66-0.70$ & 0.72 & $0.70-0.73$ \\
\hline $4+$ & 1 & & 1 & \\
\hline \multicolumn{5}{|c|}{ Length of the dry period } \\
\hline$<41 \mathrm{~d}$ & 0.67 & $0.64-0.70$ & 0.85 & $0.82-0.88$ \\
\hline 41 to $70 \mathrm{~d}$ & 0.76 & $0.73-0.78$ & 0.71 & $0.69-0.73$ \\
\hline$>70 \mathrm{~d}$ & 1 & & 1 & \\
\hline \multicolumn{5}{|c|}{ Relative last test-day milk yield ${ }^{2}$} \\
\hline$<-8.25 \mathrm{~kg} / \mathrm{d}$ & 1.604 & $1.51-1.70$ & 1.41 & $1.34-1.47$ \\
\hline-8.25 to $8.25 \mathrm{~kg} / \mathrm{d}$ & 1.169 & $1.11-1.23$ & 1.13 & $1.09-1.18$ \\
\hline$>8.25 \mathrm{~kg} / \mathrm{d}$ & 1 & & 1 & \\
\hline \multicolumn{5}{|l|}{ Calving season } \\
\hline Winter & 1.08 & $1.04-1.13$ & 1.02 & $0.99-1.05$ \\
\hline Spring & 1.21 & $1.16-1.26$ & 1.11 & $1.07-1.14$ \\
\hline Summer & 1.18 & $1.14-1.23$ & 1.15 & $1.12-1.18$ \\
\hline Fall & 1 & & 1 & \\
\hline \multicolumn{5}{|c|}{ Relative $305 \mathrm{ME}$ milk yield ${ }^{3}$} \\
\hline$<-1,549 \mathrm{~kg}$ & 0.93 & $0.87-0.98$ & 1.51 & $1.44-1.58$ \\
\hline$-1,549$ to $1,938 \mathrm{~kg}$ & 0.87 & $0.83-0.92$ & 1.11 & $1.06-1.16$ \\
\hline$>1,938 \mathrm{~kg}$ & 1 & & 1 & \\
\hline
\end{tabular}

${ }^{1} \mathrm{CI}=$ confidence interval.

${ }^{2}$ Deviated from herd-year-season average.

${ }^{3}$ Deviated from DHI provided herd mates' average.

$300 \mathrm{~d}$. On the other hand, more than $10 \%$ of the herds showed an increase of at least 10 percentage points in the risk of live culling and death when days open increased for the same categories.

The explanatory variables herd 305 ME milk yield, herd size, days dry, early lactation live cull risk, and early lactation death risk were examined for herds that showed either an increase in the risk of death or live culling for longer days open (most herds), or a decrease in the risk of death or live culling for longer days open (few herds). The risk of live culling or death on the explanatory variables was regressed with simple logistic

Table 4. Distribution of herds by the magnitude of the increase (percentage points) in the risk of death or live culling between days open categories 46 to $90 \mathrm{~d}$ and 210 to $300 \mathrm{~d}$ after calving

\begin{tabular}{|c|c|c|c|c|c|}
\hline \multirow[b]{2}{*}{ Item } & \multicolumn{5}{|c|}{ Percentile } \\
\hline & $10 \%$ & $25 \%$ & $50 \%$ & $75 \%$ & $90 \%$ \\
\hline \multicolumn{6}{|c|}{ Risk of death } \\
\hline Parity 2 & -0.37 & 1.30 & 3.46 & 6.19 & 9.63 \\
\hline Parity 3 & -0.38 & 1.29 & 3.50 & 6.21 & 9.64 \\
\hline Parity $\geq 4$ & -0.35 & 1.30 & 3.61 & 6.43 & 10.30 \\
\hline Overall & -0.97 & 1.25 & 3.76 & 7.36 & 11.52 \\
\hline \multicolumn{6}{|c|}{ Risk of live culling } \\
\hline Parity 2 & -1.68 & 0.50 & 3.36 & 6.68 & 10.70 \\
\hline Parity 3 & -1.74 & 0.50 & 3.32 & 6.57 & 10.70 \\
\hline Parity $\geq 4$ & -1.83 & 0.44 & 3.30 & 6.54 & 10.71 \\
\hline Overall & -2.65 & 0.13 & 3.45 & 7.63 & 12.61 \\
\hline
\end{tabular}




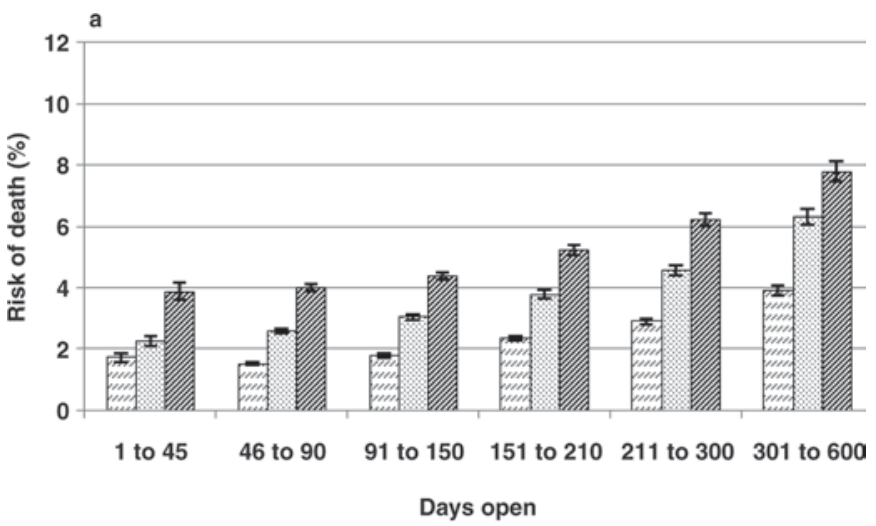

Parity 2 Parity 3 Parity 4+

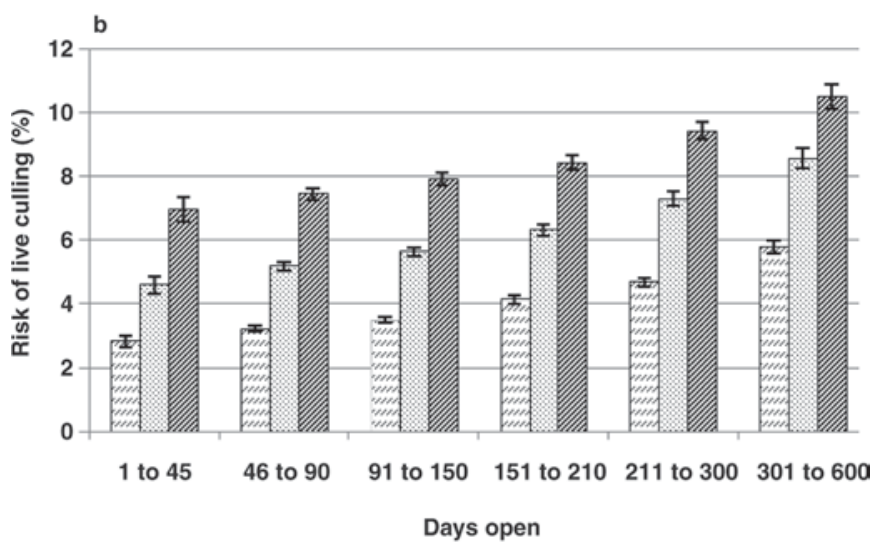

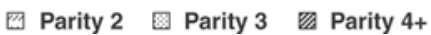

Figure 1. Risk (\%) of death (a) or live culling (b) for the 6 categories of days open in the previous parity, for second, third, and $\geq$ fourth parity. Standard errors ranged from 2.9 to $9.5 \%$ for each of the estimated least squares means (LSM) for death and from 2.4 to $6.6 \%$ for each of the estimated LSM for live culling.

regression. Odds ratios for increased live culling were $1.02(P=0.003)$ for herd size, $0.99(P=0.01)$ for days dry, and $0.96(P=0.01)$ for the level of early cull risk. Odds ratios for increased death risk were $1.04(P$ $<0.001)$ for herd size and $0.94(P<0.001)$ for the level of early death risk. The effects of other potentially explanatory variables were not significant. Therefore, larger herds and herds with fewer days dry and those that had a lower absolute risk of death in early lactation had a greater effect of days open on live culling and death risk.

\section{Interactions Between Variables of Interest and Days Open}

The interaction between days open and the variables of interest on the risk of death and live culling was significant $(P<0.001)$ but small in all the cases. As shown in Figures 1 to 5 , the association between days open and survival was not strongly affected by different levels of the variables of interest.

Parity. As expected, both the risk of death and live culling increased $(P<0.001)$ with parity. Cows in their fourth or greater parity had doubled risks of death and live culling compared with cows starting their second parity $(\mathrm{OR}=2.3)$. The greater death rate for greater parity cows has been reported previously (van Arendonk and Dijkhuizen, 1985; Thomsen et al., 2004; Miller et al., 2008). A greater risk of live culling for greater parity cows was also reported earlier (van Arendonk and Dijkhuizen, 1985; Hare et al., 2006), with increments of 20 to $30 \%$ in the risk of live culling for each parity subsequent to the first calving (Hadley et al., 2006). The effect of parity could be confounded with age, although parity was included in the model.
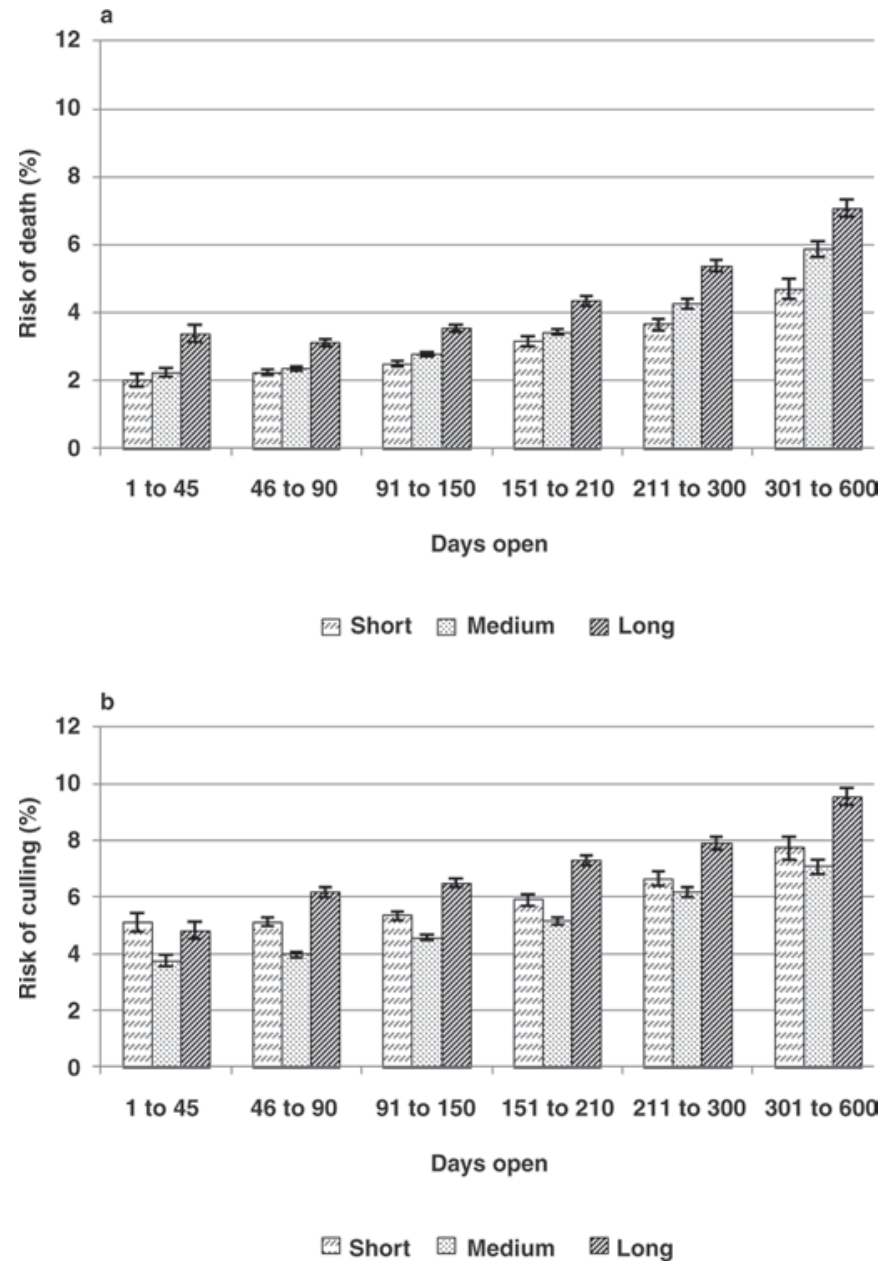

Figure 2. Risk (\%) of death (a) or live culling (b) for the 6 categories of days open in the previous parity for short, medium, and long dry period before calving. Standard errors ranged from 3.1 to $8.7 \%$ for each of the estimated least squares means (LSM) for death and from 2.5 to $6.9 \%$ for each of the estimated LSM for live culling. 

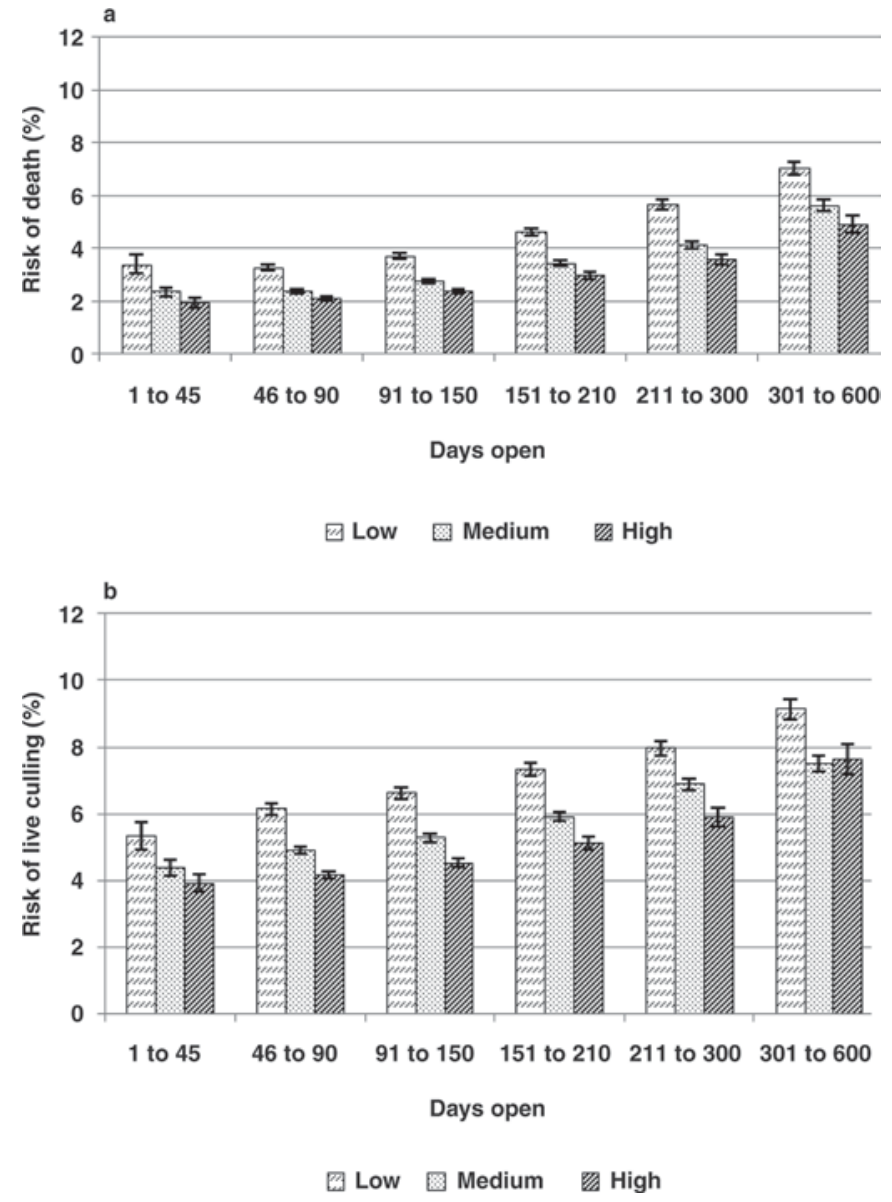

Figure 3. Risk (\%) of death (a) or live culling (b) for the 6 categories of days open in the previous parity by categories of low, medium, and high relative last test-day milk yield before dry off before calving. Standard errors ranged from 2.9 to $7.9 \%$ for each of the estimated least squares means (LSM) for death and from 2.4 to $6.2 \%$ for each of the estimated LSM for live culling.

The magnitude of the association between days open and the risk of death and live culling varied with parity and was the greatest for third parity (Figure 1). The greatest risk of death or live culling was for cows in at least their fourth parity in the category 300 to $600 \mathrm{~d}$ open in the previous parity (Figure 1).

Dry Period. Longer dry periods increased the risk of death $(P<0.001)$. The risk of live culling was greater for short and long dry periods compared with intermediate dry periods $(P<0.001$; Table 2$)$. The effect of days open on the risk of live culling and death around the next calving was the greatest for cows with a longer dry period (Figure 2). There were no changes in rank among the cross-classified categories. For mortality, short and medium dry periods resulted in a lower risk of mortality for all categories of days open. For live culling, the medium dry period length resulted in a lower risk of live culling than short dry periods for all categories of days open. The risk of death and live culling varied from 2.9 to $4.3 \%$ and from 5.9 to $6.9 \%$ for short and long dry periods, respectively (Table 1). The OR for the risks of death and live culling were 0.7 and 0.8 for short and 0.8 and 0.7 for intermediate dry period lengths, respectively, when compared with long dry periods. A clear effect of dry period length on health has not been described (Bachman and Schairer, 2003; Watters et al., 2008). An effect on risk of death was noted for longer dry periods ( $>70 \mathrm{~d}$ ), which had the greatest risk of death for all categories of days open (Figure 2).

Relative Milk Yield at Dry Off. The risk of death and live culling increased with lower relative last testday milk yield before dry off before calving $(P<0.001$; Figure 3). Cows with the low level of relative last testday milk yield were at 1.62 and 1.92 percentage points greater risk for death and live culling than cows in the high category, respectively (Table 2 ).
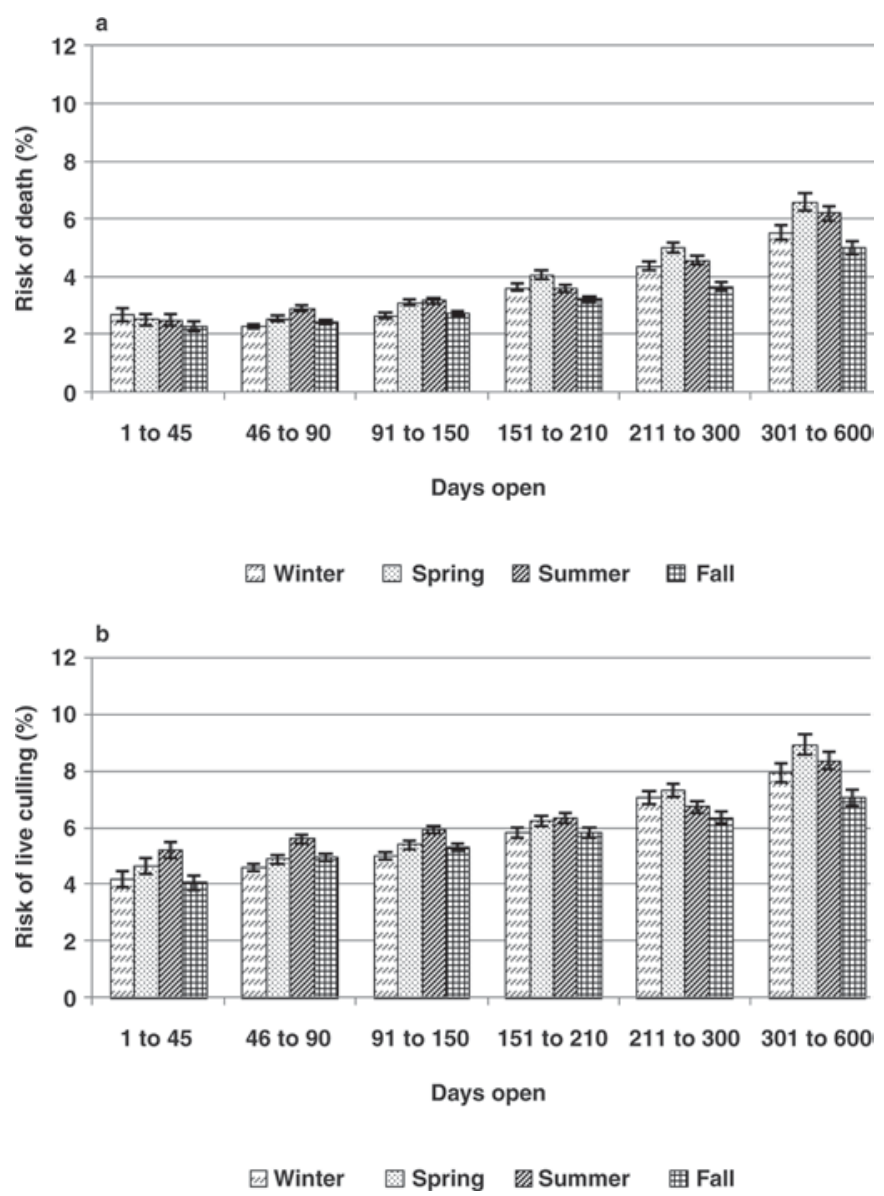

Figure 4. Risk (\%) of death (a) or live culling (b) for the 6 categories of days open in the previous parity by season of calving; winter, spring, summer, and fall. Standard errors ranged from 2.9 to $12.5 \%$ for each of the estimated least squares means (LSM) for death and from 2.4 to $10.9 \%$ for each of the estimated LSM for live culling. 

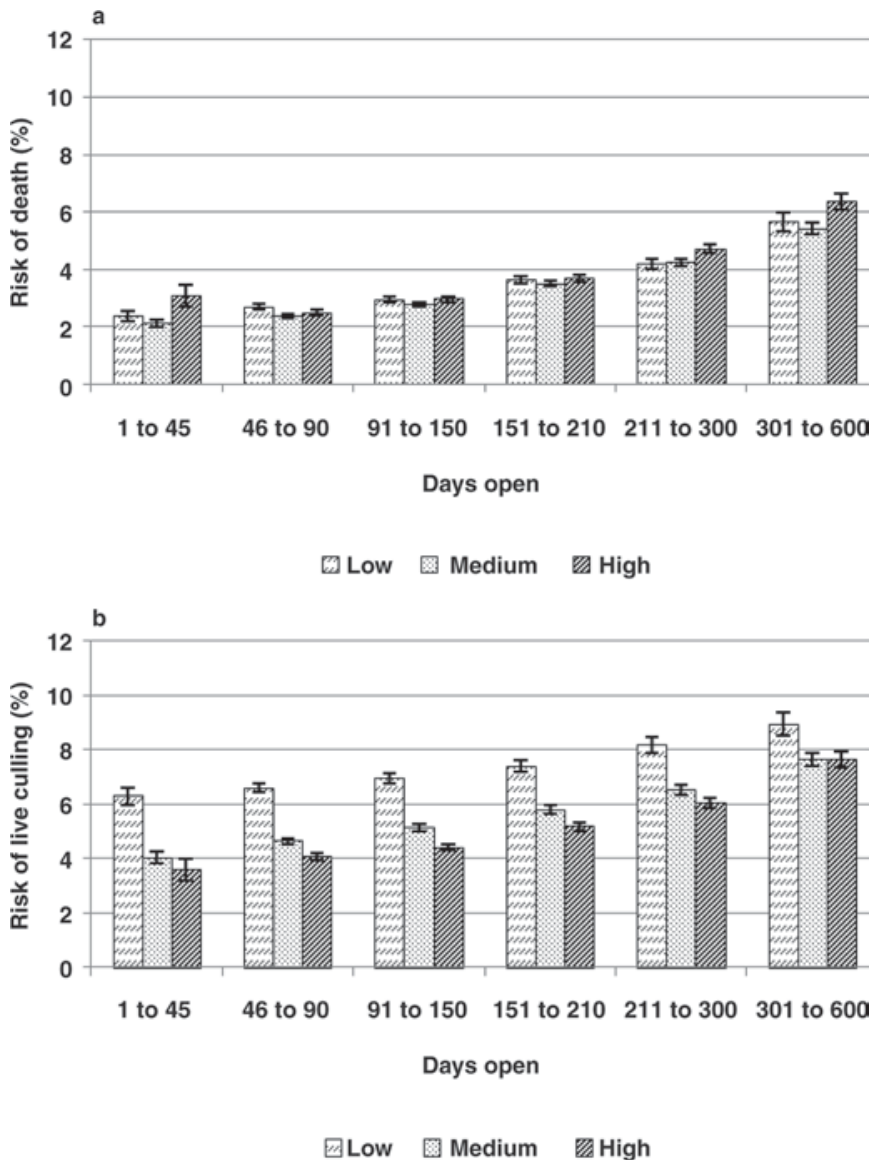

Figure 5. Risk (\%) of death (a) or live culling (b) for the 6 categories of days open in the previous parity by low, medium, and high cow's relative 305-d mature equivalent (305ME) milk yield before calving. Standard errors ranged from 2.8 to $10.5 \%$ for each of the estimated least squares means (LSM) for death and from 2.3 to $7.9 \%$ for each of the estimated LSM for live culling.

Season. Cows calving during spring and summer had a greater risk of death and live culling compared with cows calving in fall and winter (Table 3 ). These findings are in agreement with those previously reported (Miller et al., 2008); however, variable patterns of the seasonal effect among geographical regions may have reduced the magnitude of this effect. When interaction was considered, the effect of days open on the risk of death and live culling was the greatest for cows calving in spring (Figure 4).

Relative 305ME Milk Yield. Finally, cows with greater relative $305 \mathrm{ME}$ milk yield before calving had a greater risk of death, followed by low-producing cows. Miller et al. (2008) reported a trend for greater death risk in cows with greater lactation yield. Conversely, the risk of live culling decreased with greater relative 305ME milk yield. The effect of days open on death and live culling was larger for cows with intermediate and high 305ME milk yield in the previous parity, respectively (Figure 5).

Different factors may play a role in the association between increased days open in the previous parity and a greater risk of culling. An undesirable genetic relationship between fertility traits and survival has been reported (Dematawewa and Berger, 1998). Moreover, healthier cows that had a better transition after calving may be more likely to conceive promptly and may also be more likely to survive in the future.

Overconditioning as a consequence of increased days open has been mentioned earlier. Such cows may have an increased risk of metabolic disorders in the proximity of a subsequent calving, resulting in more live culling or death. Prolonged days dry together with lower milk yield at the last test-day before dry off may contribute to overconditioning of cows. These findings support the evidence for the association between cows overconditioned at calving and health problems reported by others (Fronk et al., 1980; Gearhart et al., 1990; Chassagne et al., 1999; Heuer et al., 1999). If excess conditioning around parturition is responsible for the increased risks, dairy producers might consider postponing dry-off by milking longer than normal or better managing dry period nutrition so as to avoid accumulation of excessive body fat. Further analyses examining the association between days open, health problems, body condition, and culling around calving is useful.

\section{CONCLUSIONS}

Cows with greater parity, prolonged dry period, and low relative last test-day milk yield before calving had an increased risk of live culling and death around calving. Low relative $305 \mathrm{ME}$ milk yield before calving increased the risk of live culling but not the risk of death. Increased days open from approximately 90 to $>300 \mathrm{~d}$ in the previous parity doubled the risk of live culling and death around calving. Interactions between days open and variables of interest were significant but small. Economic analysis of reproductive programs should include the increased risk of death and live culling associated with increased days open in the previous parity.

\section{ACKNOWLEDGMENTS}

The authors thank Pfizer Animal Health (New York, NY) for financial support that partly funded this study. Dairy Records Management Systems (Raleigh, NC) is acknowledged for supplying the data used in this study. 


\section{REFERENCES}

Bachman, K. C., and M. L. Schairer. 2003. Invited review: Bovine studies on optimal lengths of dry periods. J. Dairy Sci. 86:30273037.

Bar, D. Y. T. Gröhn, G. Bennett, R. N. González, J. A. Hertl, H. F Schulte, L. W. Tauer, F. L. Welcome, and Y. H. Schukken. 2008. Effects of repeated episodes of generic clinical mastitis on mortality and live culling in dairy cows. J. Dairy Sci. 91:2205-2214.

Chassagne, M., J. Barnouin, and J. P. Chacornac. 1999. Risk factors for stillbirth in Holstein heifers under field conditions in France: A prospective survey. Theriogenology 51:1477-1488.

De Vries, A. 2006. Economic value of pregnancy in dairy cattle. J. Dairy Sci. 89:3876-3885.

Dechow, C. D., and R. C. Goodling. 2008. Mortality, live culling by sixty days in milk, and production profiles in high- and low-survival Pennsylvania herds. J. Dairy Sci. 91:4630-4639.

Dematawewa, C. M., and P. J. Berger. 1998. Genetic and phenotypic parameters for 305-day yield, fertility, and survival in Holsteins. J. Dairy Sci. 81:2700-2709.

Dohoo, I., W. Martin, and H. Stryhn. 2003. Veterinary Epidemiologic Research. Atlantic Veterinary College, Charlottetown, PE, Canada.

Fetrow, J., K. V. Nordlund, and H. D. Norman. 2006. Invited review: Live culling: Nomenclature, definitions, and recommendations. J. Dairy Sci. 89:1896-1905.

Fronk, T. J., L. H. Schultz, and A. R. Hardie. 1980. Effect of dry period overconditioning on subsequent metabolic disorders and performance of dairy cows. J. Dairy Sci. 63:1080-1090.

Gearhart, M. A., C. R. Curtis, H. N. Erb, R. D. Smith, C. J. Sniffen, L. E. Chase, and M. D. Cooper. 1990. Relationship of changes in condition score to cow health in Holsteins. J. Dairy Sci. 73:31323140 .

Goff, J. P., and R. L. Horst. 1997. Physiological changes at parturition and their relationship to metabolic disorders. J. Dairy Sci. 80:1260-1268.

Hadley, G. L., C. A. Wolf, and S. B. Harsh. 2006. Dairy cattle live culling patterns, explanations, and implications. J. Dairy Sci. 89:2286-2296.

Hare, E., H. D. Norman, and J. R. Wright. 2006. Survival rates and productive herd life of dairy cattle in the United States. J. Dairy Sci. 89:3713-3720.
Heuer, C., Y. H. Schukken, and P. Dobbelaar. 1999. Postpartum body condition score and results from the first test-day milk as predictors of disease, fertility, yield, and live culling in commercial dairy herds. J. Dairy Sci. 82:295-304.

Kuhn, M. T., J. L. Hutchison, and H. D. Norman. 2007. Dry period length in US Jerseys: Characterization and effects on performance. J. Dairy Sci. 90:2069-2081.

McConnel, C. S., J. E. Lombard, B. A. Wagner, and F. B. Garry. 2008. Evaluation of factors associated with increased dairy cow mortality on United States dairy operations. J. Dairy Sci. 91:1423-1432.

Miller, R. H., M. T. Kuhn, H. D. Norman, and J. R. Wright. 2008 Death losses for lactating cows in herds enrolled in Dairy Herd Improvement test plans. J. Dairy Sci. 91:3710-3715.

Morrow, D. A. 1976. Fat cow syndrome. J. Dairy Sci. 59:1625-1629.

Oseni, S., I. Misztal, S. Tsuruta, and R. Rekaya. 2003. Seasonality of days open in US Holstein. J. Dairy Sci. 86:3718-3725.

Smith, J. W., L. O. Ely, and A. M. Chapa. 2000. Effect of region, herd size, and milk production on reasons cows leave the herd. J. Dairy Sci. 83:2980-2987.

Thomsen, P. T. A. Mette Kjeldsen, J. T. Sørensen, and H. Houe. 2004. Mortality (including euthanasia) among Danish dairy cows (1990-2001). Prev. Vet. Med. 62:19-33.

USDA:APHIS. 2007. Dairy 2007. Part I: Reference of dairy cattle health and management practices in the United States, 2007. Report from USDA:APHIS:VS: CEAH, National Animal Health Monitoring System. Fort Collins, Co. http://nahms.aphis.usda. gov/dairy/dairy07/Dairy2007_Part_I.pdf Accessed May 17, 2009.

van Arendonk, J. A. M., and A. A. Dijkhuizen. 1985. Studies on the replacement policies in dairy cattle. III. Influence of variation in reproduction and production. Livest. Prod. Sci. 13:333-349.

Watters, R. D., J. N. Guenther, A. E. Brickner, R. R. Rastani, P. M. Crump, P. W. Clark, and R. R. Grummer. 2008. Effects of dry period length on milk production and health of dairy cattle. J Dairy Sci. 91:2595-2603.

Weigel, K. A., R. W. Palmer, and D. Z. Caraviello. 2003. Investigation of factors affecting voluntary and involuntary live culling in expanding dairy herds in Wisconsin using survival analysis. J. Dairy Sci. 86:1482-1486. 